\title{
EL PALUDISMO EN FUENTE ÁLAMO DE MURCIA EN LOS SIGLOS XVIII Y XIX
}

\author{
Gregorio Castejón Porcel ${ }^{1}$ \\ Licenciado en Geografía (Universidad de Murcia). Máster en Planificación y Gestión de Riesgos Naturales \\ gregoriocastejon.um@gmail.com
}

\section{RESUMEN}

En los siglos XVIII y XIX, Fuente Álamo de Murcia se vio afectada por diversos brotes palúdicos dentro de la afección febril generalizada que afligía a gran parte del territorio nacional, especialmente al área levantina. La existencia natural de varias zonas encharcadas en el cauce de las ramblas adyacentes al núcleo poblacional, fue el detonante de estos brotes tercianarios cuyos efectos fueron especialmente graves en la población. A mediados del XVIII, Juan Antonio García Serón decidió hacerse cargo de las colosales obras que eran necesarias para iniciar el drenaje de las zonas marjalencas; pero no será hasta mediados del XIX cuando desaparecerán los problemas causados por las tercianas, gracias al intenso aprovechamiento de las aguas captadas mediante los sistemas de galerías con lumbreras existentes (el primero creado por el señor Serón en 1753 y el segundo construido por sus descendientes, pertenecientes a la familia Girón, en 1837-1840) y mediante los numerosos pozos verticales que extraían el agua del subsuelo por medio de la fuerza eólica o animal, lo que provocó el descenso de los niveles freáticos y la desaparición de las fuentes naturales que alimentaban las charcas.

Palabras clave: Paludismo, tercianas, freático, galerías con lumbreras, marjal, charca.

\section{ABSTRACT}

\section{Malaria in Fuente Alamo (18th and 19th centuries)}

In the 18th and 19th centuries, Fuente Alamo de Murcia was affected by various malarial outbreaks of the febril illness that affected much of the country, especially the Levantine area. The natural occurrence of several flooded areas adjacent to the ravine close to the populated centre, was the trigger for these outbreaks, whose effects were particularly severe on the population. In the mid-eighteenth century, Don Juan Antonio García Serón decided to take on the colossal work which was necessary to drain the marsh areas, but not until the mid-nineteenth century when the problems caused by the tertian fever disappeared. Thanks to the intensive use of water drawn through the systems of existing qanats (the first created by Lord Serón in 1753 and the second built by his descendants, La Casa de Girón in 1837 to 1840) and by numerous vertical wells which extracted the groundwater by wind or animal power, a decline in groundwater levels and the disappearance of the natural springs that fed the ponds was triggered.

Keywords: Malaria, tertians, ground water, qanat, marsh, pond.

\section{INTRODUCCIÓN}

La repercusión del paludismo sobre el municipio de Fuente Álamo de Murcia en los siglos XVIII y XIX fue muy importante, subrayando así, con estos nuevos datos desconocidos hasta ahora, el elevado grado de afectación que esta epidemia tuvo en el levante peninsular y concretamente en la Región de Murcia, donde, hasta el momento, tan solo las zonas arroceras de la ribera del Segura y El Almarjal de Cartagena habían sido identificados como focos palúdicos de primer orden en el territorio murciano.

1 Miembro de GIECRYAL (Grupo Interdisciplinario de Estudios Críticos y de América Latina). 
El conocimiento de la presencia de un manantial de agua en Fuente Álamo se tiene, al menos, desde la segunda mitad del siglo XV, aunque existen motivos que hacen pensar en un origen mucho más remoto. Sin embargo, dichas aguas supusieron siempre, y especialmente después del repartimiento de las tierras lorquinas tras la reconquista cristiana, un recurso clave para la ganadería, pues dicho lugar era aprovechado como abrevadero para los rebaños que se dirigían a pasar el invierno a los pastos del Campo de Cartagena desde las zonas del interior de España y del Reino de Murcia. Con el tiempo, especialmente a partir de los inicios del siglo XVI, en torno al manantial se fue generando un núcleo de población que creció rápidamente favorecido por la riqueza en aguas del lugar, las cuales serían aprovechadas por los pastores y agricultores gracias a su extracción mediante aceñas y pozos.

Desde entonces, además de su riqueza hídrica, la situación estratégica de Fuente Álamo será crucial en su devenir por estar ubicada en una posición ventajosa en la comarca natural del Campo de Cartagena, a mitad de camino entre la populosa y dinámica ciudad de Murcia y la ciudad de Cartagena, donde el comercio marítimo avivaba la economía. Además, se hallaba en el centro del espacio conformado por el triángulo Lorca-Cartagena-Murcia, las tres grandes urbes de la Región de Murcia entonces, y a orillas de la trascendental vereda natural de la Rambla de Fuente Álamo.

Esta relación recursos hídricos-población, parece ser que se mantuvo en equilibrio hasta principios del siglo XVIII cuando la abundancia natural de aguas y la existencia de importantes aneares, junqueras y cañaverales, propiciados por la existencia de este mismo elemento, produjo que se conformasen amplias áreas encharcadas en varios puntos de la Rambla de Fuente Álamo y de la Rambla de la Azohía. Dichas pantanos, supusieron el caldo ideal para el desarrollo del mosquito Anopheles sp. principal transmisor del parásito Plasmodium que genera el Paludismo, Malaria o como se denominaba en la época, las Tercianas. Los citados brotes palúdicos menguaron considerablemente la población de la localidad debido a las defunciones de los infectados y, principalmente, al desarrollo de un proceso migratorio de los vecinos hacia zonas alejadas del foco de infección. De esta manera, el mismo recurso natural que generó el núcleo urbano, originó, entonces, un riesgo natural que favoreció el despoblamiento del mismo y el desarrollo de gran parte de las pedanías que existen hoy día en el término municipal de Fuente Álamo de Murcia.

Ante la gravedad de la situación, el Regidor Perpetuo de Lorca, Don Juan Antonio García Serón, solicitó permiso a los Concejos de Lorca, Cartagena y Murcia (Fuente Álamo se encontraba, por entonces, dividido en estos tres concejos) para ejecutar, mediante galerías con lumbreras y presas subálveas, un plan de extracción de las aguas estancadas y proceder, posteriormente, a su aprovechamiento agrícola y como fuerza motriz para varios molinos de cubo. Concedidas las pertinentes licencias, las obras se ejecutaron aunque, según consta en los escritos, los efectos de éstas no parece que fueran los deseados hasta prácticamente mediados del siglo XIX, cuando dichos sistemas eran propiedad de la Casa de Girón, descendientes del Señor Serón.

Con todo, los orígenes de estas charcas, entonces insanos focos palúdicos, fueron estrictamente de causa natural. Por un lado, en la Rambla de Fuente Álamo son frecuentes los episodios de avenida que dejan importantes cantidades de agua en el lecho, además, en aquella época, algunos acuíferos existentes en el área de estudio se encontraban prácticamente a nivel superficial y, también, el subálveo de la rambla era muy rico en aguas ya que el cauce se veía alimentado por distintos afluentes que recogían las aguas de lluvia y aquellas que manaban en los relieves circundantes.

De esta forma, no es de extrañar que para la realización de este estudio, en primer lugar se haya trabajado en la comprensión y definición del paludismo, siendo la principal tarea para ello la realización de una atenta lectura de los distintos trabajos de marcado carácter médico-científico que abordaban la definición e investigación de tan importante enfermedad, elaborándose, posteriormente, una síntesis de dicho análisis. Además, como labor fundamental, se ha procedido a identificar los documentos referentes a la problemática indicada en relación con Fuente Álamo y recogidos en los Archivos Municipales de Fuente Álamo, Cartagena, Lorca y Murcia, así como también los existentes en el Archivo General de la Región de Murcia y otros de interés. Así, el análisis minucioso de estos recursos, tanto escritos como cartográficos, han permitido identificar los puntos donde se ubicaban las zonas encharcadas, la incidencia de éstas sobre la población y las medidas aplicadas para su erradicación. Igualmente, el trabajo de campo y el examen de bibliografía científica que analiza el área de estudio, han permitido definir qué causas naturales (y en algún caso antrópicas) originaron la presencia de los estanques de aguas que favorecieron la aparición del paludismo. 
De este modo, el objetivo prioritario de este trabajo, es dar a conocer las causas y consecuencias del paludismo sufrido en Fuente Álamo de Murcia desde las primeras referencias a la enfermedad en el siglo XVIII hasta su erradicación, aportando con ello una información desconocida hasta el momento acerca de un nuevo foco tercianario en la Región de Murcia en un periodo de acusada efervescencia palúdica en España, además de señalar las repercusiones sociodemográficas causadas por la epidemia y las soluciones aplicadas para su resolución (Castejón, 2015. a).

\section{EL ESPACIO GEOGRÁFICO DE FUENTE ÁLAMO DE MURCIA}

El municipio de Fuente Álamo, se halla situado en el sureste de la Región de Murcia, dentro de la comarca natural del Campo de Cartagena. Con un total de casi 17.000 habitantes en la actualidad, esta localidad fue fundada aproximadamente en el siglo XV estando su territorio dividido en los concejos de Lorca, Cartagena y Murcia hasta 1820 cuando se independizó de estos, configurándose con ello su término municipal (figura 1). A $20 \mathrm{~km}$ de Cartagena, 30 de Murcia y 45 de Lorca, su posición estratégica y su importante mercado de ganados, ayudaran al florecimiento de su economía y de su población a lo largo del tiempo, así como también lo hará la transformación agrícola dada en los primeros siglos de su existencia gracias al aprovechamiento de las aguas captadas por los distintos sistemas de galerías con lumbreras que desde el siglo XVIII se construyeron en éste territorio (Castejón, 2014).

Figura 1. T.M. de Fuente Álamo con la cabecera municipal situada a orillas de la rambla
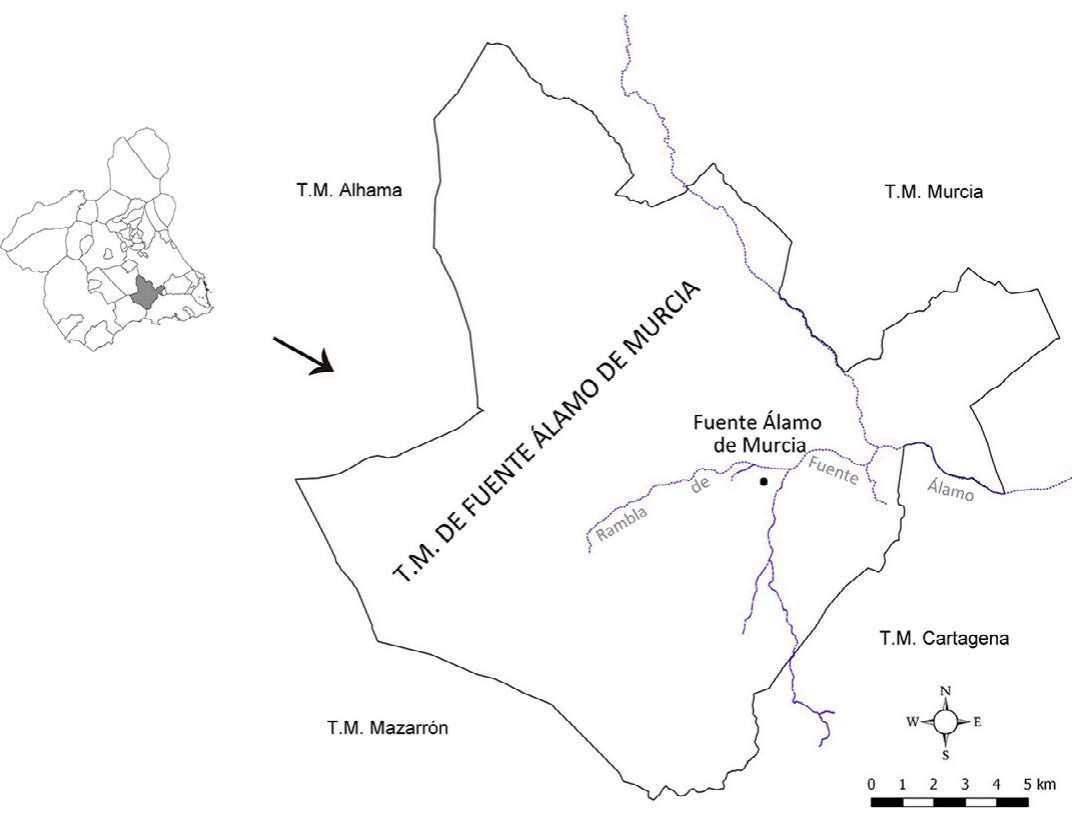

Elaboración propia

Geológicamente, el área de estudio se ubica en la cuenca neógena del Campo de Cartagena-Mar Menor, asentándose ésta sobre una extensa cuenca intrabética dividida en subcuencas relativamente profundas con orientación N-SE y rellenadas por sedimentos neógenos y cuaternarios que conforman una llanura regular escasamente inclinada hacia el Mar Menor (IGME, 1993). La zona de análisis, por tanto, es una planicie prácticamente sin ninguna alteración topográfica que sólo se ve interrumpida por el relieve del Cabezo Gordo, la Sierra de Los Victorias y el afloramiento volcánico de El Carmolí, estando la parte más deprimida de ésta ocupada por la albufera del Mar Menor, la cual está separada del Mediterráneo por La Manga, y siendo los límites naturales del Campo de Cartagena, los relieves de la alineación prelitoral de la Sierra de Carrascoy, Sierra del Puerto, Cresta del Gallo y Miravete, los relieves monoclinales de cuesta de Los Villares, Columbares, Altaona y Escalona y al este el Mar Menor.

En cuanto al clima, se da un régimen de humedad mediterráneo semiárido, con un período seco de 7 a 10 meses (Conesa, 2006) mientras que los episodios con temperaturas medias iguales o inferiores a $0{ }^{\circ} \mathrm{C}$ son prácticamente inexistentes, así como también lo son los de temperaturas menores a $3{ }^{\circ} \mathrm{C}$. Quiere 
esto decir, que el riesgo de períodos de heladas es casi inexistente. Además, los rasgos más notables de la pluviometría los constituyen su variabilidad interanual y su baja cuantía anual (Conesa, 1990), hecho que se debe a que en este territorio predominan las situaciones del oeste, aportando éstas, por lo general, estabilidad atmosférica y valores térmicos con anomalías positivas. Por ello, las jornadas con los registros más lluviosos corresponden a situaciones del segundo y tercer cuadrante, es decir, con flujo en superficie de viento marítimo de levante (este), como consecuencia de un desarrollo ciclogenético en Orán, unido a la llegada de zonas divergentes de vórtices fríos en niveles altos atmosféricos sobre la vertical de Alborán. Con ello, la entrada al Campo de Cartagena de dichos núcleos por el sur y sureste regional, desencadenan, por lo general, fuertes episodios de lluvias de alta intensidad horaria; se produce lo que se conoce como Gotas frías o DANAs (Depresión Asiladas en Niveles Altos) que generan importantes avenidas en los cauces de drenaje, las ramblas.

Si se analizan los datos del SIAM registrados por el observatorio de "Fuente Álamo (Balsapintada)", la media anual de precipitaciones (2000-2013) es de $296 \mathrm{~mm}$ mientras que en el observatorio de "Fuente Álamo (Campillo de Abajo)" y para el periodo 1994-2013, la media anual es de 241 '5 mm. Sin embargo, en este territorio se registran episodios de precipitación de alta intensidad horaria, generalmente, en el mes de otoño, que pueden llegar a descargar hasta $100 \mathrm{~mm}$ en una hora, prácticamente $1 / 3$ del total anual recogido por ambos observatorios. En cuanto a las temperaturas, la $\mathrm{T}^{\mathrm{a}}$ media anual en Balsapintada y Campillo de Abajo es prácticamente la misma, $17.5^{\circ} \mathrm{C}$, mientras que la $\mathrm{T}^{\mathrm{a}}$ media máxima absoluta es de $38.8^{\circ} \mathrm{C}$ en la primera estación y de $39.9^{\circ} \mathrm{C}$ en la segunda. Diferencia también notable en cuanto a la $\mathrm{T}^{\mathrm{a}}$ media mínima absoluta, siendo de $-1.45^{\circ} \mathrm{C}$ en Balsapintada y de $-0.81^{\circ} \mathrm{C}$ en Campillo de Abajo. Por otro lado, los valores de ETP, superan los $1.200 \mathrm{~mm}$ según la Ecuación de FAO Penman-Monteith, y las horas de sol varían de las 3.400 registradas en el observatorio de Balsapintada a las 3.300 horas del observatorio de Campillo de Abajo.

Como se puede deducir de estos datos, dada la intensa ETP que reina todo el año en la región estudiada y la larga sequía, el clima de esta zona impone serias limitaciones a la producción vegetal siempre que dichas carencias no sean cubiertas con aguas que suplan la escasez pluviométrica de la zona, como son, actualmente: las procedentes del Trasvase Tajo-Segura, las extraídas por los numerosos pozos verticales que se localizan en esta región o como fueron, en su día, las aportadas por las aceñas y los sistemas de galerías con lumbreras que existieron en Fuente Álamo (Castejón, 2014).

De igual modo, cabe apuntar que, por regla general, en todos los meses del año, a excepción de septiembre y noviembre, se registra en la zona de estudio un déficit hídrico muy acusado. Los dos máximos pluviométricos anuales se corresponden con septiembre y noviembre, aunque también puede señalarse como otro máximo anual el mes de marzo. Por el contrario, generalmente, las precipitaciones son muy escasas e incluso prácticamente nulas en el periodo estival; meses en los que claramente se alcanzan los valores máximos de temperatura, superándose con creces los $25^{\circ} \mathrm{C}$ de media en junio, julio y agosto, registrándose en este último mes los valores más elevados de temperatura, por encima incluso de los $25^{\circ} \mathrm{C}$ de media mensual.

Por otro lado, es importante señalar que en el Campo de Cartagena no existen corrientes permanentes de aguas superficiales, sino que existe una extensa red drenaje intermitente. En este caso, el sistema hídrico principal de esta comarca natural está constituido por numerosas ramblas. Éstas, recogen las aguas en los episodios de lluvia que, aunque escasos, suelen ser muy intensos, consecuencia del régimen climático y de la disposición del terreno, y las transportan a otras ramblas mayores que, a su vez, desaguan al Mar Menor o a las aguas mediterráneas del sur de la Región de Murcia. Sin embargo, algunas de estas ramblas se extinguen en la llanura del Campo de Cartagena al carecer de pendiente suficiente y haberse colmatado por los propios sedimentos que arrastran, es decir, algunas de ellas actúan en ocasiones como sistemas endorreicos.

En el caso del Campo de Cartagena, su principal colector es la Rambla de Fuente Álamo o Rambla del Albujón (también llamada Rambla del Fraile), la cual se localiza prácticamente en el centro de esta comarca. Ésta tiene su cabecera en las proximidades de dicho pueblo, aunque verdaderamente serán los relieves de Tallante y la Sierra del Algarrobo los que la nutran de agua en su cabecera. Su superficie vertiente, de aproximadamente $441 \mathrm{~km}^{2}$, está integrada por una serie de subcuencas; Entre ellas, las más importantes pertenecen a: la Rambla de La Murta, de la Cueva del Marqués, del Mergajón, de la Azohía, de Campoy y los Ramblizos de La Poza y La Fuente. No obstante, la cuenca tiene forma de abanico, enormemente ancha hasta las proximidades del centroide, fruto de los numerosos afluentes que vierten sus aguas en 
ella, y muy constreñida a partir de este punto situado entre El Estrecho y Lobosillo. Aguas abajo, hasta la desembocadura $(20$ '5 km), discurre el cauce principal sin que a él afluya ningún otro tipo de tributario, dándose en este tramo final una anchura de cuenca que no rebasa nunca los $2 \mathrm{~km}$ (Conesa, 1990).

\section{EL PALUDISMO O FIEBRES TERCIANAS COMO RIESGO NATURAL}

En el siglo XVIII, el paludismo toma el relevo, junto con otras dolencias, a la peste (Alberola, 2009). Los distintos nombres de la enfermedad, recuerdan los síntomas que origina, Fiebres Tercianas (fiebres intermitentes) y los supuestos orígenes de la misma: las zonas pantanosas, Paludismo (de "palus", terreno pantanoso), aunque su desarrollo no se dé únicamente en aguas estancadas, y los aires insanos, Malaria (mal-aire), aunque no sea correcta la concepción de su transmisión por el aire.

\section{1. ¿Qué es el paludismo y qué se entiende por fiebres tercianas?}

Los conocimientos aportados desde antiguo por los investigadores y la ciencia moderna, han permitido identificar el ciclo del paludismo: 1. El parásito Plasmodium sp. es introducido en el torrente sanguíneo por la picadura de la hembra del mosquito Anopheles sp., 2. el parásito viaja por la sangre hasta el hígado, 3. entra en las células del hígado, donde se multiplica, 4. sale de nuevo a la sangre donde infecta y destruye los glóbulos rojos en un proceso cíclico, 5. otro mosquito adquiere los gametocitos al picar al enfermo y 6. el parásito se reproduce dentro del nuevo mosquito y cierra el ciclo al pasar de nuevo a otra persona. Con todo, los síndromes clínicos atribuidos a la infección por paludismo eran conocidos siglos antes del descubrimiento de la etiología del agente responsable de la enfermedad, Plasmodium sp. y del vector encargado de su transmisión, Anopheles sp. Así, los términos conocidos históricamente como "fiebres cotidianas", "tercianas" o "cuartanas" respondían a ciclos febriles de 24, 48 y 72 horas, respectivamente, y diferenciaban distintos tipos de paludismo según el parásito invasor: a) el terciano benigno, comúnmente denominado "paludismo vivax", es producido por $P$. vivax. b) la terciana maligna, perniciosa, "paludismo estío-otoñal" o subterciano, es causada por P. falciparum. c) y, por último, el paludismo cuartano o "paludismo malariae" tiene como agente etiológico a P. malariae (Fernández, 2002).

Las tres fases típicas de la enfermedad eran el escalofrío, la fiebre alta y el sudor, por ese orden, distinguiéndose el tipo de paludismo por la duración de los accesos febriles que se corresponden con los dos ciclos de reproducción de Plasmodium sp. Además, en el estado del paroxismo malárico, el paciente experimenta un frío intenso a veces acompañado de dolor o adoloramiento de todo el cuerpo y cefalea. La temperatura aumenta y alcanza el estado febril, aun cuando el paciente continúa sintiendo frío, siendo tal su intensidad, que, posiblemente, no exista un estado patológico en los humanos que cause una sensación tan intensa de frío (Malagón, 2005).

Con todo, la influencia de la temperatura en el desarrollo de esta enfermedad es algo fundamental y que ya fue explicado en 1900 por el médico español Gil y Morte quien señaló, acertadamente, que "el parásito de las tercianas graves se desenvuelve bien en el cuerpo del mosquito cuando la temperatura ambiente oscila entre 15 y $30^{\circ} \mathrm{C}$, a temperaturas de $15^{\circ} \mathrm{C}$ o inferiores, queda estéril". Sin embargo, el otro factor importante fue descrito por el malariólogo italiano Gustavo Pittaluga quien creía que era la constancia del grado termométrico la que favorecía la endemia palúdica. En esta línea, se debe apuntar que, tanto la temperatura máxima como el tiempo que ésta se mantiene, son factores fundamentales que ralentizan o agilizan el proceso. De esta manera, la temperatura media que permite la extensión del paludismo en el hemisferio norte es de $9{ }^{\circ} \mathrm{C}$ (Fernández, 2002) y la temperatura máxima que lo limita es $45^{\circ} \mathrm{C}$ (Bueno et al., 2008). Del mismo modo, las temperaturas entre $20^{\circ} \mathrm{C}$ y $30^{\circ} \mathrm{C}$ favorecen el desarrollo de Plasmodium sp. en el cuerpo de Anopheles sp. y evitan la muerte de las larvas por bajas temperaturas. Teniendo en consideración esto, existen épocas concretas del año para el paludismo: el inicio ronda el mes de junio, el apogeo en agosto y el final de la enfermedad en otoño, sin embargo, en lugares con elevadas temperaturas el periodo puede alargarse. Aun así, no solo la temperatura es un factor clave, ya que la malaria es una enfermedad ligada claramente a las condiciones higiénico-sanitarias, a la salubridad y a la pobreza.

A colación con lo anterior, y tomando como base la ilustrativa obra de Fernández Astasio (2002), no es de extrañar que antes del siglo XX las principales medidas de erradicación del paludismo fuesen medidas básicamente mecánicas, como pudo ser la reducción del hábitat de los vectores mediante terraplenados, la nivelación de las tierras, la transformación de márgenes y la modificación permanente de la tierra, la vegetación o el agua mediante la creación de drenajes y desagües, tanto aéreos como subterráneos 
(como se dio en Fuente Álamo de Murcia). Otra de las medidas adoptadas fue la alteración de la salinidad del agua, el aumento o disminución brusca del caudal de la lámina de agua, la eliminación de la vegetación o disminución de la insolación y, por supuesto, la ubicación de los asentamientos fuera del alcance de los vectores y la mejora de la situación sanitaria de las poblaciones. Sin embargo, otra de las medidas aplicadas, y que supuso uno de los mayores descubrimientos en la lucha contra el paludismo, fue la administración de corteza de quina a los enfermos. En cualquier caso, como afirman Alberola y Bernabé, el uso de la corteza de quina se generalizó en las décadas finales del XVIII, tras las recomendaciones hechas por el Real Protomedicato en su informe emitido en 1785 (Alberola y Bernabé, 1998-1999), pero, en ningún momento se hace mención al uso de la quina en los casos de paludismo registrados en el municipio de Fuente Álamo, donde únicamente se menciona el uso de procesos mecánicos como terraplenados o canales de desagüe y, de forma extraordinaria, la construcción de sistemas de galerías con lumbreras y presas subálveas como técnicas de drenaje.

\subsection{Sintesis de la afección del paludismo en España en los siglos XVIII y XIX}

En España, el paludismo está presente prácticamente de manera constante desde principios del siglo XVIII hasta 1835, año desde el cual los registros se reducen de manera muy considerable, aunque no por esta razón causan menos estragos, y la mayor concentración de referencias a tercianas, se da desde mediados del siglo XVIII hasta finales de este mismo siglo, llamando la atención la marcada tendencia al alza registrada en el siglo XVIII y la posterior tendencia a la baja dada en el XIX.

Pese a todo, los brotes palúdicos se dejaron sentir con una virulencia especialmente llamativa en dos áreas: el levante peninsular y la zona central del país. En el área levantina, destacan: la Región de Murcia, caso de la ciudad de Cartagena, Fuente Álamo de Murcia y el área arrocera del Segura; en la Comunidad Valenciana, el área del Bajo Segura, los aledaños de La Albufereta (Alicante), el curso inferior del Turia y las zonas arroceras de la Provincia de Valencia, en especial las poblaciones próximas a La Albufera; y, por último, en Cataluña, las zonas de la Cuenca de Barberá, Llano de Urgel y Campo de Tarragona, así como también el norte de Gerona, concretamente la zona del Ampurdán. En la zona central peninsular, llama la atención la gran repercusión que tuvo en las comarcas de La Alcarria y el Campo de Calatrava. No obstante, prácticamente todo el país se vio sometido a tercianas, a excepción del noroeste donde las condiciones ambientales dificultaron la difusión de la epidemia (Castejón, 2015. b).

\subsection{El paludismo como riesgo natural en Fuente Álamo de Murcia}

\subsubsection{Contextualización regional}

En lo que se refiere a Murcia, se debe apuntar que la región fue aliada de la causa borbónica durante la Guerra de Sucesión, por lo que se vio favorecida en la política general de los Borbones, a lo que se suma el relieve que adquiere Cartagena a consecuencia de la nueva dimensión mediterránea de la política naval y la actuación favorecedora del Cardenal Belluga. De hecho, el XVIII es el siglo del florecimiento económico y del inicio de proyectos industriales, con la consiguiente recuperación demográfica de este territorio surestino. Precisamente, una de las causas fundamentales de la exacerbación palúdica será esta mejoría económica y demográfica a la que contribuirán el cultivo del arroz en las riberas del Segura y el desarrollo portuario de Cartagena. Así, El Almarjal de Cartagena y las zonas arroceras de la vega en Murcia, serán los principales objetivos a tratar en la lucha antipalúdica en el territorio murciano (Sáez y Marset, 2002), además del nuevo foco tercianario de Fuente Álamo de Murcia, hasta ahora desconocido, y Lorca, donde se registró un brote en el año 1852 en el que murieron 762 personas (Rico-Avello y Rico, 1947). Sin embargo, Cartagena se verá mayormente afectada por el paludismo, viéndose éste favorecido por la llegada de contingentes humanos militares, según la política bélica española y además por el debilitamiento físico que causaban los años de malas cosechas en el secano cartagenero (Marset et al, 1977); en palabras de Rodón y Bell:

"Las aguas llovedizas, estancadas y corrompidas en el Almarjal de esta ciudad, son a mi parecer la causa principal y el origen de ésta y las repetidas epidemias que ha sufrido este pueblo y sus inmediaciones..." (Peset y Peset, 1979).

En este estado, se tiene noticia de la existencia de brotes palúdicos en la Huerta de Murcia provocados por el cultivo del arroz tanto en el siglo XVIII como en el XIX (Sáez y Marset, 2002). En cuanto a la situa- 
ción de Cartagena, se conoce que así como en el siglo XVI y el XVII la ciudad portuaria sufrió las tercianas, en el siglo XVIII, la situación se agravó más si cabe con constantes e importantes episodios, llegando a ser tal la gravedad de la situación que la epidemia de 1761 causará el destronamiento de la Virgen del Rosell como patrona de la ciudad en detrimento de la Virgen de la Caridad, al parecer, más benefactora a las suplicas de sus vecinos contra estas inclemencias (Sáez y Marset, 2002; Marset et al, 1977; Rico-Avello y Rico, 1947; Rodón y Bell, 1787). Más tarde, el siglo XIX no deparará unas noticias mejores, registrándose importantes episodios tercianarios a lo largo de la centuria igual de temibles que los de la anterior (Hernández, 2003). Pese a todo, el "Proyecto de ensanche, reforma y saneamiento de Cartagena" supuso un gran cambio y un beneficio para la ciudad, además de ayudar a solucionar gran parte de los problemas que propiciaban los brotes palúdicos.

En 1891, Montaldó y Pero (1891) dice en su obra "La ciudad de Cartagena [...] ha fijado más de una vez la atención de este Ministerio y del Cuerpo de Sanidad por sus malas condiciones higiénicas, origen de un paludismo que constituye casi una endemoepidemia constante" además de apuntar que "motivo sobrado para hacer de Cartagena una de las poblaciones más expuestas á sufrir los efectos del paludismo, pudiendo en este sentido compararse á las situadas en las proximidades de los campos pantanosos donde se cultiva el arrozó de los que están sujetos a los estragos de la malaria" (Montaldó, 1891). A colación con esto, Hernández Ferrer (2003) recupera de Montaldó (1891) el siguiente dato:

"las intermitentes palúdicas, que por término medio anual causan 271 victimas en toda la provincia de Madrid [...] matan 68 individuos en Cartagena”.

En lo que se refiere a Fuente Álamo de Murcia, existen referencias concretas a brotes palúdicos en 1753, 1770, 1818 y 1822, sin embargo, las alusiones a las enfermedades que provocaban las charcas adyacentes al núcleo urbano, serán constantes, tanto en el siglo XVIII como en el siglo XIX, llegando a ser los efectos del paludismo sobre la población extremadamente graves.

\subsubsection{Origen de las aguas de los pantanos de Fuente Álamo de Murcia}

Puesto que tanto la fuente del álamo como los distintos puntos de los que brotaba agua en la Rambla de Fuente Álamo lo hacían de manera natural, es imprescindible conocer la procedencia de dichas aguas y el porqué de su abundancia. Al analizar cuál es el origen de las aguas que generaron las áreas marjalencas que existieron en las ramblas circundantes a Fuente Álamo, se llega a la conclusión de que éstas tenían tres procedencias distintas que en ocasiones podían coincidir en el tiempo y en el espacio.

En primer lugar, se debe hacer referencia al subálveo de la rambla, ya que, como se ha apuntado con anterioridad, la Rambla de Fuente Álamo es el gran colector del Campo de Cartagena. De esta forma, tanto las aguas de lluvia como aquellas que pudieran manar de manera natural en los relieves que circundan esta llanura, son conducidas en cabecera por pequeñas ramblas y cañadas hasta la Rambla de Fuente Álamo. Es por ello, que el subálveo del citado cauce que atraviesa la población de Fuente Álamo de Murcia, se ve beneficiado por dichos aportes y, por tanto, no es de extrañar la riqueza hídrica que éste poseyó siglos atrás.

En segundo lugar, además de estas someras reservas que pudieron acumularse en el propio subálveo del lecho del cauce, fue igualmente importante la existencia en la zona de estudio de acuíferos con niveles freáticos muy superficiales que aportaron agua a las zonas encharcadas y alimentaron el sistema de galerías con lumbreras del Señor Serón y posteriormente de sus descendientes, la familia Girón. En este sentido, ya se ha comentado que el Campo de Cartagena, lugar en el que se inscribe el área de estudio, se ubica en una de las grandes depresiones post-manto de las Cordilleras Béticas dándose el hecho de que sobre un substrato metamórfico se han depositado potentes rellenos de materiales del mioceno al cuaternario (Conesa, 2006) los cuales suelen ser bastante permeables y que pueden actuar a modo de acuífero libre por lo que cuando el nivel piezométrico es lo suficientemente alto, se suelen manifestar como un estanque de agua superficial o un flujo de agua corriente de escasa velocidad. Estos acuíferos, en la mayoría de las ocasiones, subyacen bajo manantiales activos, lagos y arroyos, e incluso cuando estacionalmente se da un periodo seco por la bajada del nivel freático, ya que pueden subyacer bajo cuencas y cursos secos. Descripción que sin duda coincide con lo que ocurría en las ramblas adyacentes a Fuente Álamo de Murcia.

A colación, según la Confederación Hidrográfica del Segura, bajo la superficie del espacio territorial que compone el municipio de Fuente Álamo, se localizan cuatro acuíferos: Carrascoy, Campo de Cartagena, Los Molares-Lorente y Lo Alto-La Pinilla. A su vez, si se analizan los Mapas Hidrogeológicos del Campo 
de Cartagena confeccionados por el Instituto Tecnológico Geominero de España, se puede observar cómo esta comarca natural se halla sobre cinco acuíferos bien diferenciados, que de más antiguo a más moderno son: Acuífero Triásico de Los Victorias, Acuífero Tortoniense (Mioceno), Acuífero Andaluciense (Mioceno superior), Acuífero Plioceno y Acuífero Cuaternario. En referencia a estos, tanto el primero como el último, son los que contaban con aguas más superficiales hallándose éstas a profundidades salvables para la captación mediante galerías con lumbreras y presas subálveas. Ambos acuíferos se encuentran dentro del ya citado acuífero del "Campo de Cartagena, Sistema 48, o Unidad del Mar Menor" correspondiéndose este sistema con una amplia llanura que alcanza una extensión de $1.570 \mathrm{~km}^{2}$ en la que están incluidos los términos municipales de La Unión, Cartagena, Fuente Álamo de Murcia, Murcia (con Lobosillo), Torre Pacheco, San Javier y San Pedro del Pinatar, y una parte de los términos de Orihuela y San Miguel de Salinas de la provincia de Alicante (ITGE, 1991).

Finalmente, el tercer factor que coadyudó a la formación de los estanques fueron las avenidas de agua dadas en las ramblas como consecuencia de episodios de lluvia de alta intensidad horaria o de precipitación acumulada importante. En este sentido, son muchas las referencias que existen siglos atrás acerca de avenidas producidas en esta rambla y que afectaron a la población de Fuente Álamo. De tal forma que una vez que la avenida ha pasado, en las zonas depresionarias del lecho se producen acumulaciones de agua que terminaban siendo importantes focos palúdicos en el pasado.

\subsubsection{Los pantanos antes de las primeras obras de drenaje realizadas en 1753}

Además de conocer cuál fue la posible procedencia de las aguas que alimentaban los pantanos existentes en las inmediaciones de Fuente Álamo de Murcia, es igualmente importante definir los puntos concretos donde dichos estanques se encontraban. Teniendo en cuenta lo anterior, el documento más antiguo en el que se tiene constancia de la fuente del alamo data de 1463 aunque el citado manantial, indudablemente, surgiría en una época anterior. Esta primera noticia acerca de la existencia de la fuente del álamo, emplazada en la margen derecha de la rambla que atraviesa la población (junto al Puente de San Francisco y bajo donde hoy se encuentra el hito que delimitaba los términos de Lorca, Cartagena y Murcia), estuvo motivada por el deslinde de los concejos de Cartagena y Lorca en el que se toma dicha fuente como punto de ubicación del primer mojón de esta delimitación. Sin embargo, pese a la existencia de dicha fuente natural o manantial, no se registraron incidencias relacionadas con el paludismo en el siglo XV hecho que seguramente se deba a que no sería hasta principios del siglo XVI, aproximadamente 1520, cuando empezó a asentarse la población en las cercanías de la citada fuente que, hasta este momento, era prácticamente solo un lugar de paso y abrevadero de los ganaderos en sus desplazamientos.

Este inicio de ocupación de los terrenos colindantes a la fuente del álamo, fue consecuencia de los trabajos de repoblación emprendidos desde 1500 por parte del Concejo de Lorca; entre estos, se encuentran las 200 mercedes dadas en Campo Nubla entre 1520 y 1620 por este mismo Concejo. Entre estas mercedes, en 1527, se recoge la Merced a Don Alonso Ponce de León regidor de todo lo que labren los vecinos de Librilla, en Campo Nubla cabe la Fuente el Alamo, así de Labor como de cualquier edificio, sin perjuicio de tercero y sin que lo pudiera vender a forastero (Ortega, 1991). Algunos años después, en un plano fechado en 1543 y que se encuentra recogido en el Archivo Municipal de Lorca, se representa el lugar de Campo Nubla y la fuente del álamo siendo éste el primer documento cartográfico de la existencia de este manantial de agua en torno al cual se fue concentrando la población. En 1559, según Ortega Merino (1991), los Herederos de Don Sebastián Vicente tienen que vender sus tierras en Campo Nubla por las deudas contraídas por las epidemias aunque no se hace mención a qué tipo de epidemias, sin embargo, puede que ésta sea la primera referencia a personas afectadas por paludismo como consecuencia de las aguas estancadas en el lecho de la Rambla de Fuente Álamo pero al no especificarse qué tipo de enfermedades favorecieron dicho desplazamiento, no se puede afirmar tal hecho.

Sin lugar a dudas, la primera referencia concreta que se posee acerca de la existencia de aguas estancadas o empantanadas en la Rambla de Fuente Álamo se remonta a 1642, cuando el Rey Felipe IV donó "sus aneares, tres casas principales y sus carnicerías a Don Luis Torres para que pudiese ostentar el titulo de Caballero Egregio" (Ortega, 1991). Tan solo unos años después, está documentado que en 1700, el vecino de Fuente Álamo, Don Antonio de Exea, excavó una poza en el lecho del Ramblizo de la Poza con el fin de acumular las aguas que brotaban del subsuelo de la misma, hecho que favoreció la acumulación de agua en este punto y los problemas palúdicos posteriores, mucho más notorios con el estío. 


\subsubsection{Los pantanos después de las primeras obras de drenaje.}

Medio siglo después, en 1753 tiene lugar el hito más importante en lo que se refiere a la lucha antipalúdica en el municipio de Fuente Álamo de Murcia; Don Juan Antonio García Serón, Regidor Perpetuo de la ciudad de Lorca, informado del lamentable estado en el que se encontraba dicha población como consecuencia del paludismo, decide solicitar permiso para desecar dichos marjales y aprovechar las aguas captadas. En este estado, ya que el territorio de Fuente Álamo de Murcia pertenecía a tres administraciones distintas (Lorca, Murcia y Cartagena), el Señor Serón debió solicitar permiso a estos tres concejos. En el informe de tramitación de la solicitud emitida a la autoridad de Lorca y recogida en el acta del día 16 de Junio de 1753 de este Concejo, se incluye la primera explicación del origen de los marjales y la primera descripción del lugar donde se ubicaban dichos estanques:

“...que el orijen de aquellas es de cinquenta años a esta parte poco mas o menos que se alumbro su remanse por parte de Antonio de Exea de la misma bezindad con ocasion de abrir una poza para el habio de su hacienda, que a dado el nombre a dha rambla o cañada,..."(AML, Libro de Actas Capitulares de 1753).

Además, parte de este informe dice así:

"hallaron que a la Ynmediacion de diez ò doze Baras del camino Publico que de esta ciudad ba à otro Lugar principian umedades y a distancia de otras cinco ò seis baras se Insepeccionan algunos manantiales de agua y siguiendo dha Rambla asta el numero de mil setecientas treinta varas continuan y en ellas se Recojen algunas Lagunas y en esta distancia no puede Reconozerse a punto fixo donde Nazen las augas ó tienen su origen por la expesura de matas anea caña y otras que Inposibilitan ber su Nazimiento dha Distancia que toda es en el propio de esta ciudad y sus costados el que fenerido se encuentra un Carril ò Puente y por la derecha se halla el termino de la ciudad de Cartagena y por la Izquierda el de la de Murcia...en el agua, que en la parte superior y proxima del naze en la cañada ô rambla que llaman de la poza termo de esta ciud, a causa de formar un valle muy montuoso de Aneas, Junqueras y varias fustas, que hazen un estanque de mas de mill varas de latitud en la inmediazion del expresado Lugar termino y vezindario dsta dha Ciud y sigue el de las dos enunziadas por lo corrompido de las aguas en la zitada distancia, pestilente fetor; y nozivos vapores que produze siendo asi que en el extremo con poca diferenzia de aquella se sumerjen desaparezen con publica y privada utilidad..." (AML, Libro de Actas Capitulares de 1753).

Posteriormente, el 21 de Agosto de 1753, tras la petición elevada al Cabildo de Cartagena, el Ayuntamiento decide aceptar su solicitud, como así lo recoge el Libro de cabildos celebrados por esta ciudad 1752-1753. Por otro lado, en cuanto a la solicitud hecha al Concejo de Murcia, el día 20 de Octubre de 1753 en las actas del citado Concejo se incluye la petición que a la letra dice:

"... á causa que en la parte superior de su poblacion, Termino de la ciudad de Lorca se reconocen repetidas Lagunas de agua con muy crecido monte de aneas, sisca, y junqueras que hacen corrompidas las aguas cerca de dos mil varas del Termino de la Ciudad de Lorca, y lo mismo siguen dhas Lagunas en lo respectivo a las jurisdicion de V.S. y de la de Cartagena..." (AMM, Legajo 3944, 13).

Afortunadamente, las tres ciudades concedieron permiso a Don Juan Antonio García Serón para realizar los trabajos de desecación de las zonas encharcadas que se extendían desde las inmediaciones de la confluencia de la Rambla de Fuente Álamo con la de la Poza hasta las de ésta primera con la de la Azohía. Pero las obras no tuvieron los efectos deseados de forma inmediata ya que en 1770 se tiene constancia de que el cura del pueblo huyó del mismo por miedo a las tercianas.

Más tarde, a fines del siglo XVIII la situación no mejoró y las aguas seguían alimentando los aneares existentes en las ramblas y acrecentando, de este modo, el foco palúdico que estas áreas marjalencas suponían. De esto se tiene constancia al quedar registrado en 1793 el cobro de 180 reales de vellón por el arbitrio de los aneares de la rambla por parte del Ayuntamiento (Ortega, 1991). Del mismo modo, en 1795 se elaboró un mapa anónimo de las ramblas colindantes al lugar de Fuente Álamo (figura 2), donde además de representarse la citada población, se señalan detalladamente las ramblas circundantes a ésta y los puntos donde se encontraban los estanques de aguas.

Igualmente, el 1 de junio 1798, Don Lorenzo Martínez confecciona su "Plano que manifiesta la línea divisoria de los campos de Lorca y Cartagena" en cuya definición, al explicar el punto A, expone:

"A...Lugar de Fuente-alamo la mayor parte arruinado por lo poco saludable de su temperamento qual se atribuye à efecto de las aguas del Pantano num ${ }^{\circ} 2$ ". 
Figura 2. Mapa de la zona de Fuente Álamo y Rambla del Albujón en el que se identifica con la letra "D" la ubicación de los marjales existentes en la inmediación de la localidad. Como se aprecia, dichos estanques se encontraban en la confluencia de la Rambla de Fuente Álamo con la de la Poza y la Azohía

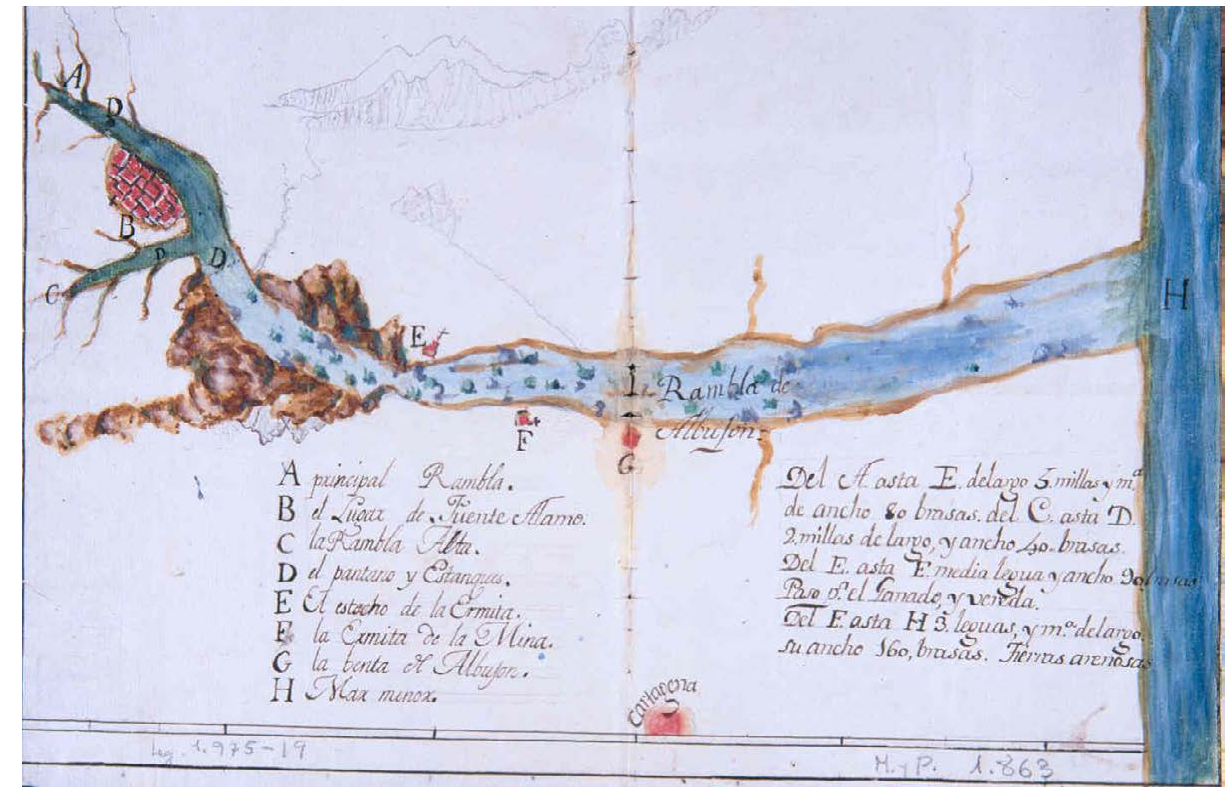

Fuente: Archivo Histórico Nacional.

En dicho documento cartográfico, del cual existe una copia en el AMFA, al igual que en el comentado plano del año 1795 , se señalan concretamente los puntos donde se encontraban los marjales de aguas e igualmente se aprecia la localización y extensión de la población y las tierras de cultivo adyacentes a ésta. Del mismo modo que en el anterior, las charcas se identifican en la confluencia de la Rambla de Fuente Álamo con la de la Azohía y el Ramblizo de la Poza. No obstante, la propia creación de esta cartografía ayuda a comprender la dimensión del problema y la especial importancia que la existencia de dichos marjales tuvo sobre la población y las autoridades, pues la elaboración de tales documentos cartográficos no era tarea ni sencilla ni barata.

Más tarde, en 1820, Fuente Álamo conseguiría de nuevo el título de villazgo durante el Trienio Liberal y se colocaran los mojones que delimitaban su término municipal independizándose así de los Concejos de Lorca, Cartagena y Murcia a los que había estado subordinado hasta la fecha. Sin embargo, desafortunadamente, tampoco en los inicios del siglo XIX quedó solucionado el problema palúdico puesto que en 1822 fue tal la gravedad de las epidemias que llegó a quedar el pueblo prácticamente abandonado y lleno de escombros. La virulencia de las tercianas condicionó que en 1822, el Ayuntamiento de Fuente Álamo de Murcia, reunido con la Junta de Sanidad, elaborara un informe acerca de la situación que corrobora que la situación epidémica no se corrigió. En las actas que hacen referencia a esta reunión, se lee:

"lo epidémico y contagioso de Tercianas [...], a motivado la emigración tan completa que en la actualidad esta reducido el Pueblo en nueve Casas abitadas habiéndose revisado en el, una Población agrícola de mas de Cuatrocientas..." (Ortega, 1991).

En este sentido, se tiene constancia de que el pueblo pasó de tener unos 240 vecinos en 1755, según el Catastro del Marqués de la Ensenada, y unos 2.700 antes de la Guerra de la Independencia (1808-1814) (Madoz, 1850), a quedar en la localidad unas 9 casas habitadas, unos 40 vecinos, en 1822 debido a que "la causa eran las repetidas lagunas de agua con muy crecido monte de aneas, siscas y junqueras que hacen corrompidas las aguas [...] motivando pestilente hedor y nocivos vapores que causan dichas enfermedades" (Ortega, 1991). En este mismo año de 1822 y aprovechando la situación de debilidad de la población debido a las consecuencias de la guerra y las epidemias, la pedanía de Cuevas de Reyllo trata de hacerse con la alcaldía invocando como principal razón "que lo epidémico y contagioso de Tercianas de este Terreno a motivado la emigración tan completa que en la actualidad está reducido el pueblo en nueve Casas abilitadas"(AMFA. Actas de 1822). Finalmente, los vecinos de Cuevas de Reyllo logran alzarse con la capitalidad del municipio en 1836 accediendo a ello el Gobernador Civil de la Provincia el 20 de Abril de 1836, 
"atendiendo al estado actual de decadencia y despoblación en que se halla Fuente-Álamo", y siendo muchos los reproches de los vecinos ante tal decisión, como el caso de Don Martín Sánchez García, quien dijo:

“... será buscar solo el estravio e incomodidad de este Becindario, y quitar a este Pueblo las regalías que disfruta de un tiempo inmemorial, y añadiendo que la mira que lleva dho Ayuntamt $t^{\circ}$ no son sola la de trasladarse a las Cuevas por si solo y si trasladar igualmente la Parroquia so color de las enfermedades estacionales que dicen se padecen solamente en dho Pueblo siendo claro que igualmente las hay en toda la Jurisdicion algunos años..."(Ortega, 1991).

El propio Ortega Merino (1991) afirmará, en referencia a estos motivos dados por los de Cuevas de Reyllo para trasladar allí la municipalidad, que "Es más lógico pensar que la mucha afluencia de los veneros del subsuelo, hacian brotar las aguas a flor de tierra, siendo el origen de las fiebres antes y de las notorias ganancias de los que las explotaban, después".

Figura 3. Detalle del plano de Sánchez Pescador; con línea azul se dibuja la canalización de la Casa de Girón y señalados con la letra "a" se identifican los puntos en los que se empantanaba el agua

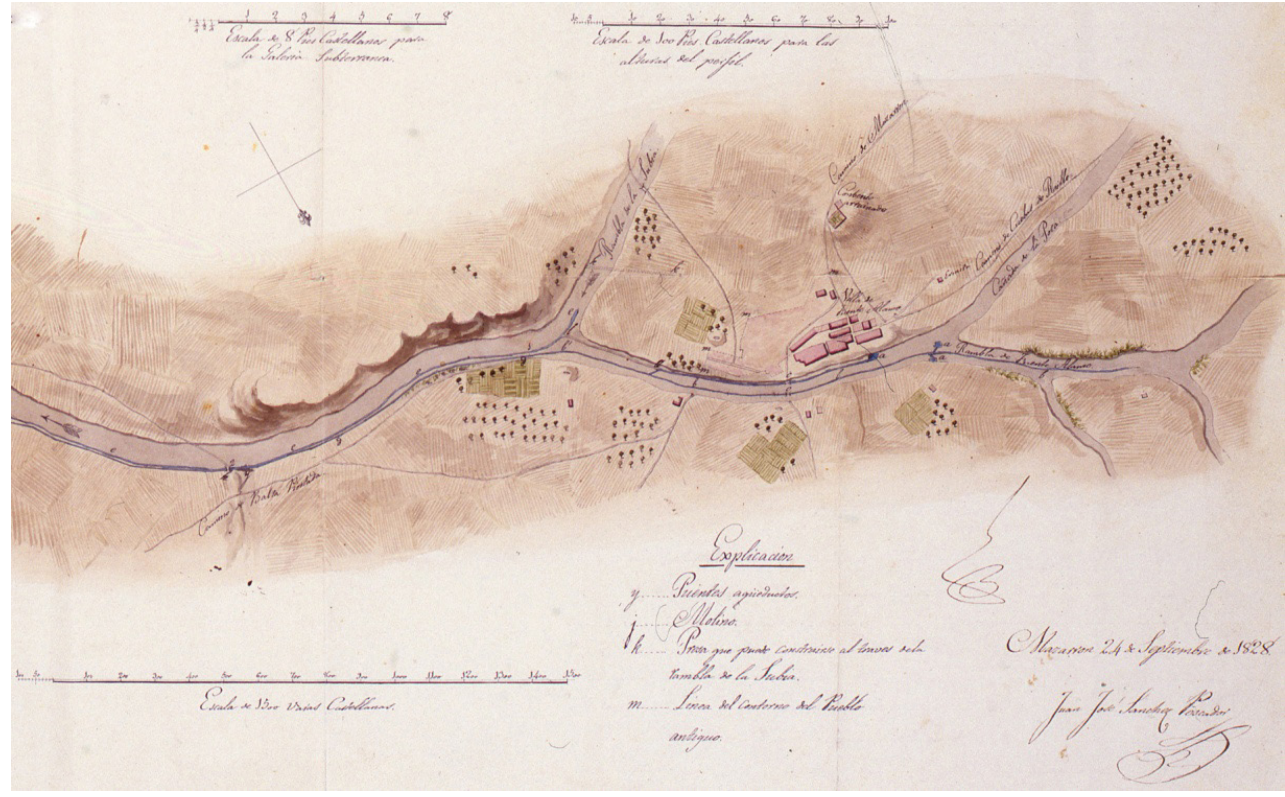

Fuente: Archivo Histórico Nacional

Más tarde, pese al vacío documental que existe, el "Plano Topográfico de la Villa de Fuente Alamo y sus alrededores, con las obras egecutadas por la Casa de Girón para la iluminación de las aguas que se hallan en su termino y las que se deven practicar para la completa reunión de las mismas" (figura 3), elaborado por Don Juan José Sánchez Pescador en Mazarrón el 24 de Junio de 1828, no deja ninguna duda en lo que se refiere a si la familia Girón ejecutó o no obras para la iluminación de las aguas y abastecimiento de un molino antes de 1828, hecho que ya corroboró el propio Catastro del Marqués de la Ensenada elaborado para esta villa en 1755. Como se aprecia al estudiar este plano, en el año 1828, el sistema de galerías con lumbreras construido por el señor Serón, era ya propiedad de sus descendientes, la familia Girón, y con él ya se habían captado las aguas subálveas y subterráneas existentes en la zona de confluencia del Ramblizo de la Poza con la Rambla de Fuente Álamo y aquellas que manaban en la primitiva fuente del álamo; canalizando ambas por las dos márgenes de la Rambla de Fuente Álamo, alimentando así las galerías construidas con las aguas subálveas del lecho de la rambla mediante, al menos, dos presas subálveas. Pero, aun así, de nuevo parece que los trabajos fueron insuficientes pues en 1837 comienzan las obras de captación de aguas en la confluencia de la Rambla de la Azohía con la de Fuente Álamo, hecho por el cual el 10 de julio de 1837 se forma la Junta de Sanidad la que emite un informe en el que dice:

"...se hicieron varias reflexiones muy detenidamente acerca de si seria ó no perjudicial a la salud publica las obras que se intentan acer por la Casa de Giron para el saque de las aguas de las ramblas de esta Poblacion, [...] y que siendo muy frecuentes y repetidas las calenturas estacionales que se padecen en este pueblo, y las inundaciones, aciendose perniciosas y malginas en el estio respecto ser la causa de esta plaga la suciedad de 
las aguas detenidas de esta Rambla hasta que le conbencio que la bariedad que en el aumento y malgnidad de este mal en el verano, hes por la fermentacion que cause el calor en ciertas epocas, parages y sitios pantanosos. Haver exsaminado de nueva esa union y como individuo de esta Junta de Sanidad, informado de la obra que se intenta practicar como a unos trescientos a cuatrocientos pasa del pueblo en la indicada Rambla, [?] de decir en beneficio de la vecindad que es [?] oportuna ala salud publica, semejante disposicion; [?] lugar por carecer punto aproposito para ello abiendo otras en que poder acerlo las bentajas a este becindario, y en segundo lugar porque deberificarlo puedan a la [?] del Pueblo, es decir a la parte arriba y mas proxima al becindario un decir es el agua detenida ó inflitrada para lo que es indispensable se grave secas, y mas esta mortifera causa que con [?] y Justicia reclaman las Leyes Sanitarias y la umanidad doliente a cuyas [?] y conformara los SS componentes de esta Junta de Sanidad (AMFA, Libro de acuerdos de 1837).

Tan solo tres años después, en 1840, se dan por finalizadas estas nuevas obras de iluminación de aguas que se sumaran a las ya elaboradas por el señor Serón a mitad del siglo XVIII. Pese a las importantes labores llevadas a cabo (las cuales serán analizadas en futuros trabajos del autor), la presencia de agua en el subálveo de la rambla seguía siendo muy importante como así lo corrobora la existencia en el lecho de la propia Rambla de Fuente Álamo de importantes cañaverales, como es el caso del cañaveral de Don Pedro Olivares quien en 1844 tenía la obligación de pagar un canon al ayuntamiento por la explotación del mismo. Tan solo un año después, el 20 de septiembre de 1845 se emite el "Expediente instruido sobre queja del vecindario por los estanques de las aguas en la rambla de esta población" por el cual se exige a Don Esteban de Cisneros, responsable de la Casa de Girón en ese momento, "que en el termino de quince dias se seque en un todo los estanques resulten originados al curso natural de las corrientes" (AMFA, Legajo 1, Actas capitulares de 1845).

A continuación, la siguiente referencia que se tiene acerca de las consecuencias del paludismo en Fuente Álamo y la situación en que ésta población se encontraba por este motivo, se remontan al año de 1850 cuando Don Pascual Madoz al describir el lugar de Fuente Álamo decía así:

"La v. que hemos descrito contaba antes de la guerra de la Independencia 600 CASAS, las que como hemos manifestado han venido á quedar reducidas á 30; las tropas de uno y otro ejército por una parte, pero más principalmente por el abandono en que las dejaron sus moradores, originaron la completa desolación de la pobl.: el abandono fue ocasionado por la atmósfera tan mefitica que formaron los vapores de las aguas pantanosas que manaban y confluían á las ramblas que tiene próximas, las que por no tener salida se estacionaban y corrompían, originando unas calenturas tan malignas, que huian por librarse de la muerte todos los vec. de esta v.; en la actualidad tienen salida aquellas aguas por dos acequias que la conducen á regar varios trozos de tierra de la dip. de Lobosillo y Los Ríos, del Campo de Murcia y la Aljorra y Mina del de Cartagena, dando después impulso a varios molinos harineros. A beneficio del destancamiento de las espresadas aguas, la pobl. se va aumentando, se construyen de nuevo muchas casas, se disfruta de un CLIMA muy saludable y no está lejano el día en que esta v. tenga la importancia que en años anteriores" (Madoz, 1850).

Como se puede extraer de la lectura de este texto, parece ser que la situación sanitaria de la Villa de Fuente Álamo mejoró a mediados del siglo XIX gracias a la construcción de las galerías que captaban las aguas del subálveo de las ramblas colindantes a la población. Sin embargo, en 1852 Don Constantino Germán elabora, a petición del Gobernador Civil, un "Informe sobre las enfermedades endémicas de este pueblo", recogido en el AMFA (Legajo 4), en el que expone una información minuciosa y de enorme interés sobre el estado de las áreas encharcadas. En primer lugar muestra su teoría acerca del origen de las lagunas manifestando que su procedencia radicaba en las aguas que venían de los relieves circundantes a parar al fondo de la rambla donde una capa impermeable muy superficial impedía la filtración de las mismas hacia capas inferiores y, por tanto, favorecía que se estancasen en el lecho de la rambla. Dicha información se pone de manifiesto al leer sus palabras:

"...De todo ello resulto que a la inmediacion de la Villa de Fuente Alamo pasa una rambla llamada del Fraile en direccion de Poniente á Levante a la cual vienen a salir varios afluentes de la parte del Mediodia conducidos por bajo del terreno donde tiene su asiento la Villa y por el demas arriva de la misma, como la parte mas baja que presenta el terreno [...] por consiguiente esto manifiesta que el deposito que produce las fuentes se renueva y que existe en alguna de las sierras ó cordilleras que encierra la cañada estensa en que se halla situada la Villa de Fuente Alamo, ó tal vez mas distante y conducida por algun terreno permeable o veta de arena, puesto que todo el [...] aluvion ó de acarreo, viene a salir por el punto que se a manifestado superior y anteriormente á la rambla...". 
Una vez identificada la procedencia de las aguas, no tarda en exponer que dichos marjales son la causa de que el paludismo esté presente en la localidad “...Proceda de donde quiera el resultado es que los afluentes vienen á parar á la rambla, que esta se estancan y empantanan de agua en parte aunque por lo general interiormente en el fondo de la misma y que la detencion de las aguas produce vapores o emanaciones en particular durante el estio que sin otra causa bastaria para dar lugar a las calenturas intermitentes que se padecen...".

A continuación, Don Constantino, manifiesta la existencia de otros factores que contribuyeron a la formación de las charcas en el fondo de la rambla. Por un lado, señala como factor fundamental la existencia de cañizares en el lecho y las nefastas consecuencias de arrojar carros de piedra al cauce de la misma con el objetivo de elevar el terreno y colmatar los estanques:

“...Pero lo que mas poderosamente ha contribuido al estancamiento de las aguas y al endurecimiento del terreno que forma el cortado derecho y el fondo de la rambla son los cañizares que hemos mencionado, que no solo se hallan en la ladera derecha y humeda, sino que se han estendido por el fondo de la rambla, sobre todo en la parte superior é inferior al punto donde se detienen las aguas; y los carros de piedra que se han echado en este mismo punto para ocultar el agua enlagunada en las ocasiones que mas se presentava á la superficie de la rambla en dicho punto y para lebantar el terreno de la misma rambla..."

Por otro, define como factor negativo que también contribuyó a la formación de los estanques, la existencia de las presas subálveas construidas por Don Juan Antonio García Serón y sus descendientes con el objetivo de drenar las aguas:

“...Al levantamiento del fondo de la rambla, han contribuido tambien poderosamente dos presas interiores ó enterradas que en el dia, una en la parte superior de la rambla y que es la de peores resultados, y otra en la inferior, destinadas á detener el agua procedente de las filtraciones para que se traspase a una mina que cruza la rambla...".

Finalmente, el autor del informe realiza una detallada descripción topográfica del terreno y los sistemas de las minas de agua y presas subálveas de la entonces propietaria de estas canalizaciones, la familia Girón. Además, expone una serie de medidas encaminadas a solucionar el problema de los estanques entre las que se menciona el arranque de los cañares existentes, la retirada de las piedras vertidas en el lecho, el arado del mismo con el fin de mejorar la filtración de las aguas y una serie de modificaciones en las acequias y minas de agua existentes orientadas a mejorar su labor de drenaje.

Figura 4. Localización de los estanques de aguas señalados en los documentos históricos de los distintos archivos y en los mapas de Anónimo (1, 5 y 4) en ¿1795?, Lorenzo Martínez (1 y 3) en 1798 y Juan José Sánchez Pescador (1, 2 y 3 ) en 1828

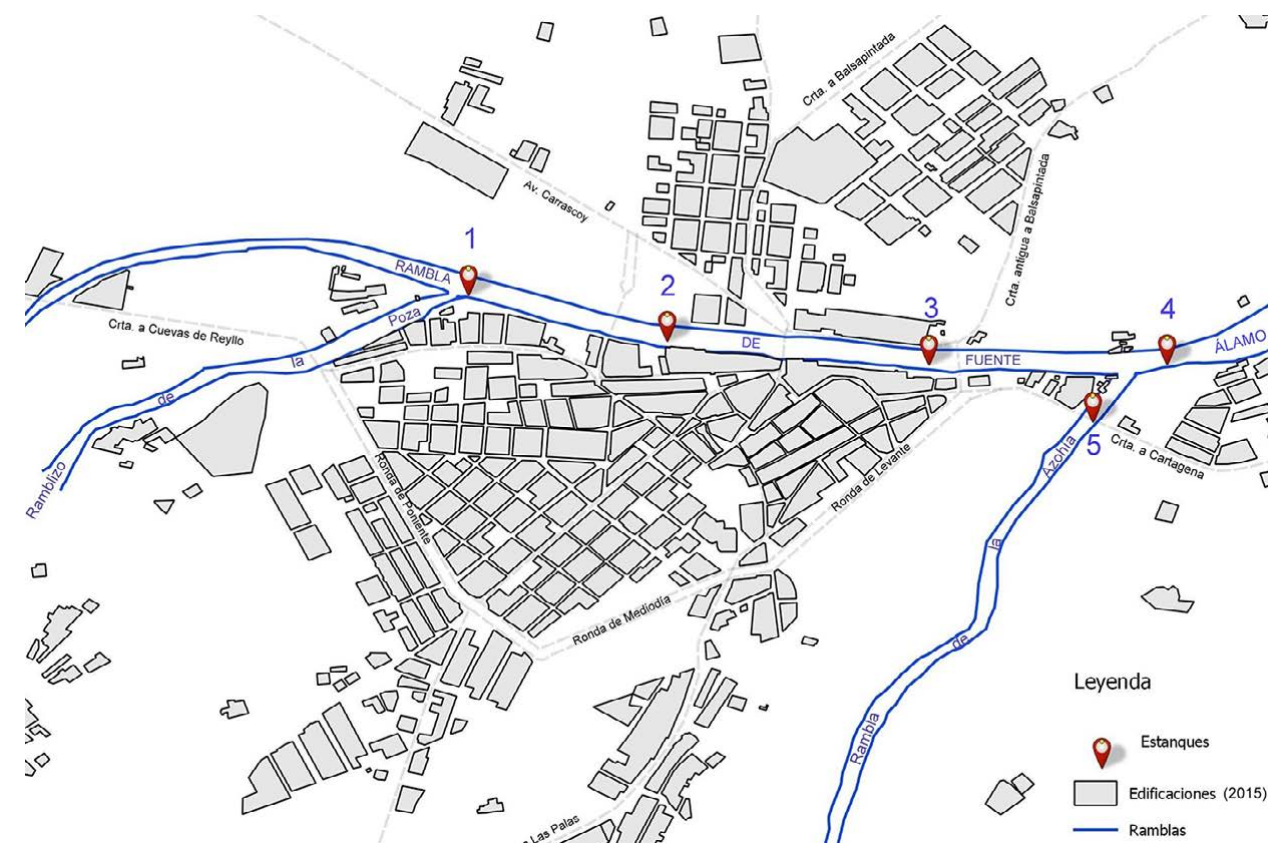

Elaboración propia mediante SIG a partir de la documentación y cartografía histórica 
Pocos años después de este informe, en 1856, se dice que la situación había mejorado accediendo de nuevo el Ayuntamiento de Fuente Álamo de Murcia al cultivo de cañares en la rambla, hecho que además nos permite conocer que, pese a todas las obras realizadas, todavía el lecho de la rambla tenía la suficiente humedad como para cultivar este producto tan demandado por entonces. Sin embargo, parece ser que las tercianas no volvieron a afectar a la población y, por tanto, los estanques debieron desaparecer ya a mitad del siglo XIX. No obstante, queda claro que las charcas o pantanos naturales se ubicaban en la confluencia del Ramblizo de la Poza y la Rambla de Fuente Álamo, frente a la fuente del álamo (junto al actual Puente de San Francisco) y en la confluencia entre la Rambla de la Azohía y la Rambla de Fuente Álamo (figura 4), como así lo corroboran los documentos y los mapas y planos anteriormente analizados. Pese a ello, la propia dinámica de los estanques provocaría la alteración espacio-temporal de su localización a lo largo del tiempo tanto por sus propias condiciones naturales como por la incidencia de las actividades humanas.

\subsubsection{Los efectos del paludismo sobre la población de Fuente Álamo}

Los efectos de la malaria sobre los vecinos del municipio de Fuente Álamo, fueron especialmente importantes (figura 5), más si cabe en el núcleo de la cabecera municipal. A finales del siglo XVII, 1684, se registra en la localidad una población de 207 habitantes (Ortega, 1991). Cifra que aumentará hasta los 240 vecinos en 1755, según lo registrado en el Catastro del Marqués de la Ensenada, y a 670 en 1785, según Ortega Merino (1991). Sin embargo, a partir de entonces se produce un descenso acusado de la población, registrándose un total de 396 habitantes en 1804 (Ortega, 1991). Incluso existe constancia de que las epidemias provocaron en 1818 (Pascual Madoz señala que fue en 1823) el abandono, por parte de los monjes franciscanos del Convento Franciscano de San Bernardino de Siena que se hallaba ubicado en esta localidad, al menos, desde 1629.

Posteriormente, pese a que se produce un aumento notable del número de vecinos en el término municipal, alcanzándose la cifra de 1.600 habitantes en 1822, sin embargo, los escritos recogen que en la localidad propiamente dicha de Fuente Álamo de Murcia, tan solo existían 9 casas habitadas (unos 36 vecinos) (Ortega, 1991). Más adelante, en 1846 se constata la "escasez de vecinos" como así lo recoge el Acta capitular del día 10 de Enero, aunque no se detalla el número de estos. Por estas fechas, entre 1845-1850, Pascual Madoz contabiliza en su obra un total de 30 casas habitadas (unos 120 vecinos); a partir de entonces, el crecimiento de la población es imparable, en 1857 son 1.464 los vecinos de la villa, como así se recoge en el Acta capitular de la sesión del Ayuntamiento del día 7 de abril de 1857, mientras que en 1890 se registran 1.900 habitantes (AMFA, Acta Capitular de 1890) y en 1900 un total municipal de 9.964 (CARM).

Figura 5. Evolución demográfica de la localidad de Fuente Álamo de Murcia en la que se aprecia la gran repercusión negativa que tuvo el paludismo sobre ésta desde finales del S.XVIII hasta mediados del XIX. (*) Se refiere al total municipal.

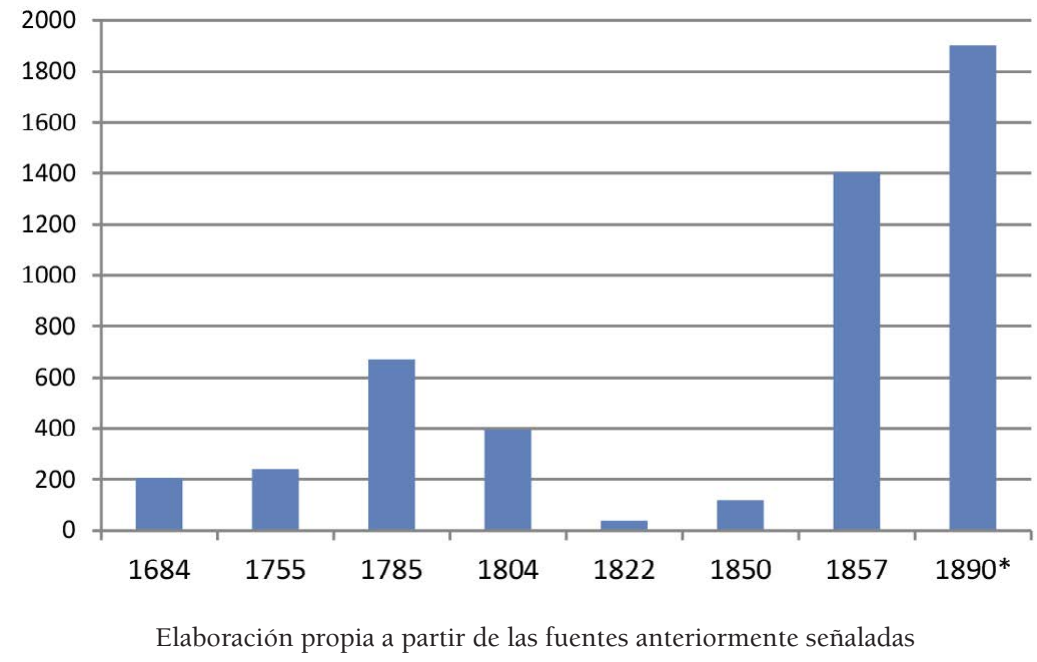

No obstante, los descensos de población se debieron a las defunciones provocadas por la enfermedad y, especialmente, a que la mayoría de los vecinos de esta localidad huyeron del pueblo y se instalaron en 
otros puntos del municipio alejados de los focos palúdicos y, por tanto, mucho más seguros. Este hecho, será el que propiciará el crecimiento y, en muchas ocasiones, la génesis de las distintas pedanías que salpican en la actualidad el territorio de Fuente Álamo de Murcia y casi logra convertir a la cabecera municipal en un pueblo fantasma.

\section{CONCLUSIONES}

Los resultados obtenidos en este trabajo de escala local ofrecen una ventana a la situación en la que se encontraba gran parte del territorio nacional español en el periodo de estudio, y permiten disponer, ahora, de datos de este nuevo foco palúdico fácilmente contrastables y extrapolables a otras regiones españolas que se vieron azotadas por el paludismo en los siglos XVIII y XIX. Así, preferentemente, la incidencia de los brotes palúdicos sobre los habitantes de Fuente Álamo y su distribución temporal guardan, notorias similitudes con gran parte de las poblaciones que se vieron afectadas en el levante, especialmente con los casos de la Comunidad Valenciana o Cataluña (Giménez, 2008; Alberola y Bernabé, 1998-1999; Cavanilles, 1795-1797; Arranz, 1985; Peset y Peset, 1979 y Masdevall, 1786).

De este modo, queda demostrado que durante los siglos XVIII y XIX la población de Fuente Álamo de Murcia se vio severamente afectada por diversos brotes tercianarios (palúdicos) como consecuencia de la existencia, en las ramblas adyacentes a esta localidad, de importantes zonas encharcadas que se veían alimentadas naturalmente por los aportes subálveos de la rambla, aquellos que procedían de la existencia en el área de estudio de unos acuíferos muy superficiales y por las contribuciones derivadas de importantes episodios de avenida que dejaban considerables cantidades de agua en el lecho del cauce. Con todo, se puede afirmar que una serie de factores naturales de carácter topográfico, hidrogeológico y climático, provocaron el origen de estos pantanos que se localizaban en distintos puntos de las ramblas que se encuentran en las inmediaciones de la localidad de Fuente Álamo de Murcia, concretamente en la Rambla de Fuente Álamo, Rambla de la Azohía y Ramblizo de la Poza.

Los citados marjales, fueron el elemento ideal para la proliferación del mosquito transmisor del paludismo, hecho que favoreció el contagio de los vecinos del municipio y, por ello, unos valores alarmantes de mortalidad y emigración de los pobladores de la localidad hacía zonas alejadas de los focos palúdicos, lo que causó un abandono casi total del núcleo poblacional en varias ocasiones y que incluso conllevó el traslado temporal del Ayuntamiento a la pedanía de Cuevas de Reyllo en 1822.

Pese a que en esta época el paludismo no era una enfermedad desconocida en otras regiones de España ni en la propia Región de Murcia, hasta el momento, no se conocían los nefastos avatares que debió sufrir el municipio murciano que se estudia en este trabajo y que tan profundamente afectaron a su evolución demográfica y a la composición de su término municipal, provocando acusados descensos poblacionales que dejaron en varias ocasiones prácticamente arruinada y vacía la localidad.

Ante la alarmante situación de emergencia que las consecuencias del paludismo estaban causando, a mediados del siglo XVIII, el Regidor Perpetuo de la Ciudad de Lorca, Juan Antonio García Serón, ideó un singular y complejo sistema de drenaje de las aguas subálveas mediante galerías con lumbreras y presas subálveas, a semejanza del empleado en Lorca para abastecer la Fuente del Oro, ya que el Señor Serón había sido el encargado (en dos ocasiones) de reparar el sistema que abastecía la fuente lorquina. El resultado de la aplicación de este sistema como método drenante, supondrá un hecho que difícilmente se repitió en el territorio nacional, sin embargo, permitió la captación efectiva de un volumen importante de agua que era aprovechada para riego, tras libre subasta, y como fuerza motriz para un molino harinero de dos cubos propiedad de los propietarios del cauce. Molino que supuso un gran complejo industrial y que resultó ser una edificación muy singular en el Campo de Cartagena puesto que en el resto de la comarca solo se tiene constancia de otro molino de cubo más, el construido por la Casa de Girón entre 1847-1840 en la Finca Casa Grande.

A colación con ello, es necesario añadir que pese a que tanto en el siglo XVIII como en el siglo XIX ya se conocían las cualidades febrífugas de la quina, en ningún momento se menciona su uso en los enfermos de Fuente Álamo de Murcia. De manera que únicamente los medios mecánicos empleados, técnicas de drenaje, arranque de cañares, limpieza del cauce,... constituyeron las técnicas empleadas en la lucha contra el paludismo.

Pese a todo, los resultados no fueron inmediatos y hasta mediados del siglo XIX todavía seguían estando presentes los efectos que las tercianas causaban a la población de esta localidad del Campo de 
Cartagena. Afortunadamente, aunque lenta, la desecación de los citados pantanos supuso una mejora de las condiciones de salubridad traducida en un incremento de la población y un crecimiento urbano.

Así, este trabajo, supone un ejemplo de población afectada por paludismo en los siglos XVIII y XIX en la que se intentó solucionar los problemas generados por esta epidemia de una manera ingeniosa, costosa y que finalmente terminó siendo útil, frenando así las graves consecuencias socioeconómicas que ésta estaba causando sobre la población la enfermedad.

\section{REFERENCIAS}

Alberola Romá, A. y Bernabé Gil, D. (1998-1999). Tercianas y calenturas en tierras meridionales valencianas. Una aproximación a la realidad médica y social del siglo XVIII. Revista de historia moderna (17), 95-112. Alicante: Universidad de Alicante, Dpto. Historia Medieval, Historia Moderna y Ciencias y Técnicas Historiográficas.

Alberola Romá, A. (2009). De la percepción popular a la reflexión erudita. La transmisión de la "cultura de la catástrofe" en la España del siglo XVIII. Les Travaux du CREC en Ligne, 39-67. Paris: Centre de Recherche sur l'Espagne Contemporaine, Université de la Sorbonne Nouvelle.

Arranz, M. (1985). Epidèmies i crisis agràries a la Catalunya Nova en els decennis de 1720: l'actitud de les autoritats borbòniques. Aplec de Treballs, (7), 193-216. Montblanc: Centre d'Estudis de la Conca de Barberà.

Baudron, P. (2013). Anthropisation d'un système aquifer multicouche méditerranéen (Campo de Cartagena, SE Espagne). Approches hydrodynamique, géochimique et isotopique. (Tesis). Montpellier: Universidad de Montpellier.

Bueno Marí, R. y Jiménez Peydró, R. (2008). Malaria en España: Aspectos entomológicos y perspectivas de futuro. Revista Especial de Salud Pública, 82 (5), 467-479. Madrid: Ministerio de Sanidad, Servicios Sociales e Igualdad.

Castejón Porcel, G. (2014). Galerías con lumbreras (qanats) en Fuente Álamo de Murcia: sistemas históricos de captación y canalización de aguas. Fuente Álamo de Murcia: Ayuntamiento de Fuente Álamo de Murcia.

Castejón Porcel, G. (2015). Galerías con lumbreras y presas subálveas como sistema drenante de áreas palúdicas en Fuente Álamo de Murcia (SS.XVIII-XIX). En: de La Riva, J.; Ibarra, P.; Montorio, R. y Rodrigues, M. (Eds.) Análisis espacial y representación geográfica: innovación y aplicación. (pp.59-68). Zaragoza: Universidad de Zaragoza-AGE. (a)

Castejón Porcel, G. (2015). Paludismo en España en los siglos XVIII y XIX: Distribución espacial y erradicación. En: de La Riva, J., Ibarra, P., Montorio, R., Rodrigues, M. (Eds.). Análisis espacial y representación geográfica: innovación y aplicación. (pp. 69-78). Zaragoza: Universidad de Zaragoza-AGE. (b)

Cavanilles, J. A. (1795-1797). Observaciones sobre la historia natural, geografía, agricultura, poblaciones y frutos del Reyno de Valencia. Madrid: Imprenta Real.

Conesa García, C. (1990). El Campo de Cartagena. Clima e Hidrología de un medio semiárido. Murcia: Editum.

Conesa García, C. (Ed.) (2006). El Medio Físico de la Región de Murcia. Murcia: Editum.

Contreras Mas, A. (1980). Epidemiología rural mallorquina a fines del S.XVIII. Treballs de geografía (7), 83-90. Palma de Mallorca: Universitat de les Illes Balears.

Giménez Font, P. (2008). La epidemia de malaria de 1783-1786: Notas sobre la influencia de anomalías climáticas y cambios de usos del suelo en la salud humana. Investigaciones geográficas (46), 141-157. Alicante: Instituto Interuniversitario de Geografía de la Universidad de Alicante.

Gómez Espín, J.M.; Castejón Porcel, G. y Gil Meseguer, E. (2012). Un modelo de captación y conducción de aguas en medios semiáridos: el Canal del Sifón de Fuente Álamo de Murcia. En: Gómez Espín, J.M. y Hervás Avilés, R. M. (Coord.), Patrimonio hidráulico y cultura del agua en el Mediterráneo (pp. 227-248). Murcia: Fundación Séneca, Campus Mare Nostrum y AECID.

Fernández Astasio, B. (2002). La erradicación del paludismo en España: Aspectos biológicos de la lucha antipalúdica. (Tesis doctoral). Madrid: Universidad Complutense de Madrid. 
Hernández Ferrer, F. I. (2003). Análisis epidemiológico de la mortalidad en Cartagena (1871-1935) y semántico-documental de las expresiones diagnósticas. (Tesis doctoral). Murcia: Universidad de Murcia.

IGME (Instituto Geológico Minero Español) (1993). Mapa geológico de España. Fuente-Álamo de Murcia. Hoja y Memoria $n^{\circ}$ 955. Escala 1:50.000. Madrid: IGME.

ITGE (1991). Las aguas subterráneas en España. Estudio de síntesis. (1991). $2^{a}$ edición. Madrid: Instituto Tecnológico Geominero de España.

Madoz Ibáñez, P. (1850). Diccionario Geográfico-Estadístico-Histórico de España y sus posesiones de ultramar. Madrid: Establecimiento tipográfico de P. Madoz y L. Sagasti.

Malagón, F. (2005). El origen del paroxismo malárico. Revista Médica del IMSS, 43 (1), 83-88. Méjico: Instituto Mexicano del Seguro Social.

Marset Campos, P; Chacón Jiménez, F; Lemeunier, G; Ramos García, E; Saturno Hernández, J; Nicolás Marín, M. E; Valera Candel, M. y Ferrandiz Araujo, C. (1977). La sociedad murciana y cartagenera y las epidemias durante los SS. XVII, XVIII y XIX. V Congreso Nacional de Historia de la Medicina, 1 (pp. 177-208). Madrid: SEHM.

Masdevall, J. (1786). Relación de las epidemias de calenturas pútridas y malignas que en estos últimos años se han padecido en el Principado de Cataluña... Madrid: Imprenta Real.

Mateu Tortosa, E. (1987). Arroz y paludismo: Riqueza y conflictos en la sociedad valenciana del siglo XVIII. Valencia: Edicions Alfons el Magnànim, Institució Valenciana d'Estudis i Investigació.

Montaldó y Peró, F. (1891). Cartagena. Estudios topograficomédicos de la localidad é histórico-médicos y clínicos de la epidemia de cólera que sufrió en 1885. Madrid.

Ortega Merino, R. (1991). Crónica de Fuente-Álamo (A través de seis siglos). Fuente Álamo de Murcia: Ayuntamiento de Fuente Álamo de Murcia.

Peset Reig, M. y Peset Reig, J. L. (1979). Tercianas y ciencia médica en el Setecientos valenciano. I Congreso de Historia del País Valenciano, III (pp. 685-694). Valencia: Universidad de Valencia.

Pittaluga, G. (1903) Investigaciones y estudios sobre el paludismo en España. Madrid.

Rico-Avello y Rico, C. (1947). Aportación española a la historia del paludismo. Madrid.

Rodón y Bell, M. (1787). Relación de las epidemias que han afligido a la ciudad de Cartagena, sus causas, y método curativo arreglado a los mas celebres Autores: y la exposición del nuevo método especifico descubierto por el Medico Camara de S. M. Don Josef Masdevall, mandado establecer de Orden del Rey, los felices efectos que han resultado de su uso, y algunas utiles reflexiones. Cartagena: Pedro Ximenez.

Sáez Gómez, J. M. y Marset Campos, P. (2002). Teórica, Académica y práctica ciudadana en el paludismo. Las causas de las enfermedades endémicas en Murcia durante el S. XVIII desde la perspectiva de la Administración Local. Asclepio, LII, 167-183. Madrid: Instituto de Historia (CSIC). 